\title{
Application Research of Internet Plus in University Student Work
}

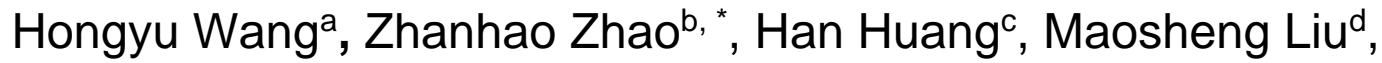 \\ Chaoyang Liu ${ }^{e}$ and Huijuan $\mathrm{Fu}^{\dagger}$ \\ School of Information and Safety Engineering, Zhongnan University of Economics and Law, \\ Wuhan 430073, China. \\ awanghongyu@znufe.edu.cn, bzhaozhanhao0575@foxmail.com,chuanghan@znufe.edu.cn, \\ d317815195@qq.com, elcy@znufe.edu.cn, ‘290795200@qq.com
}

\begin{abstract}
With the Internet Plus Action Plan proposed, major domestic traditional industries in China took an active part in seeking deep integration with the Internet, which forms a brand new industry status and promotes the economic growth. Moreover, the higher education, an important cause of social evaluation, encounters new challenges. Student work, the basis of higher education, has to characteristics of keeping pace with time. Therefore, it's definitely necessary to efficiently fuse the flourishing Internet and lagging student work management pattern. With the integration of Internet plus and student work as starting point, we put forward and implemented a mobile information service system, called Campus Micro-Platform. This mobile Internet system deploys student work within ideological collection and guidance, student transaction processing, information and notice transmission, communication between student and school counsellors, etc. It provides original thinking for the application of Internet Plus in university student work. Besides, according to the feedback information of this system in Zhongnan University of Economics and Law, we proved the system's popularization value.
\end{abstract}

Keywords: Student work; Internet Plus; information service platform; empirical study.

\section{Introduction}

With the continuous propulsion of Internet Plus Action Plan by Chinese government, domestic traditional industries are seeking for cohering with Internet actively [1, 2]. Higher education, an important part of social development, has possessed rich human resources and combined high-quality social hardware resources, therefore, which undertakes the task of national innovative development. It is well worth to combine Internet with higher education, for the exploded development would carry out. Student Work is the implementing foundation of higher education, however, the thinking of student work under the circumstance that mobile Internet has become a newly normality is still lagging behind. Several prominent questions in student work still exist, such as the inconvenience communication between students and teachers, the tedious processing of student affairs, the uncontrolled information spreading and so on.

There is a contradiction requirement between efficient information acquisitions and lagging information providing, which is the main problem in student work [3]. College students may be effected by negative information easily, consequently, violence incidents and ideological problems in campus may happen. Otherwise, information in mobile Internet environment has four new features, including convenience, interactivity, timeliness and specificity, which proves that information provided pattern of student work should be updated and transformed in the Internet age. In addition, how to provide students with campus information services which adapt to the times required, has become a problem undertaken by student work to be solved in the current environment [4].

Our paper took difficulties and shortcomings of current student work into consideration, which combined with empirical research results, considered the actual demand of teachers and students synthetically. Therefore, we put forward a new method to carry out student work, that was to develop a new mobile campus information service platform based on Internet Plus Action Plan. We called this original platform as Campus micro platform, which is aimed at promote student work the sound and fast development. Campus Micro-Platform, a relatively perfect information service model, is based on the mode and idea that other mobile Internet products has been widely used, emerges as the 
times require. Besides, it has been token student work in Zhongnan University of economics and Law (hereinafter, ZNUFE) as a practice case.

\section{Opportunities and Challenge}

The Campus Computing Project, a large-scale research project, was launched and hosted by Professor Kenneth Green at Claremont Graduate University in 1990. It was the first appear of digital campus concept. As the construction of the digital campus becoming more and more thorough, it is no doubt that student work in university got a fantastic transformation opportunity and is facing an unprecedented challenge. [5]

\subsection{Opportunity Brought by Internet Plus of the College Students Work.}

Almost every college student is glad to express their thoughts and feelings within social Networking sites. Several school counsellors mentioned a conception called self-expression during interview, which originated from medical field and firstly proposed by psychologist Jourard [6, 7]. It was defined as a process of certain individual passing information to others, sharing your thoughts and feelings. Self-expression making is a mental decision process of social individual. Selfexpression behaviour under social Networking sites circumstance has grown explosively in the wave of mobile internet. Furthermore, teachers considered that student work can make a great progress if the information collected from social Networking can be used appropriately.

Students have showed great demand of information resource in the information age. The rapid develop of the mobile internet and the spawn of the new media provide a new pattern to dissemination of information. Teachers can send the information kind that students are interested in. By the way, the raise of the mobile communicate application such as WeChat, QQ brought a new plat form to the communication between teachers and students so that school counsellors can catch the students' ideological trends and guide the students to a correct direction.

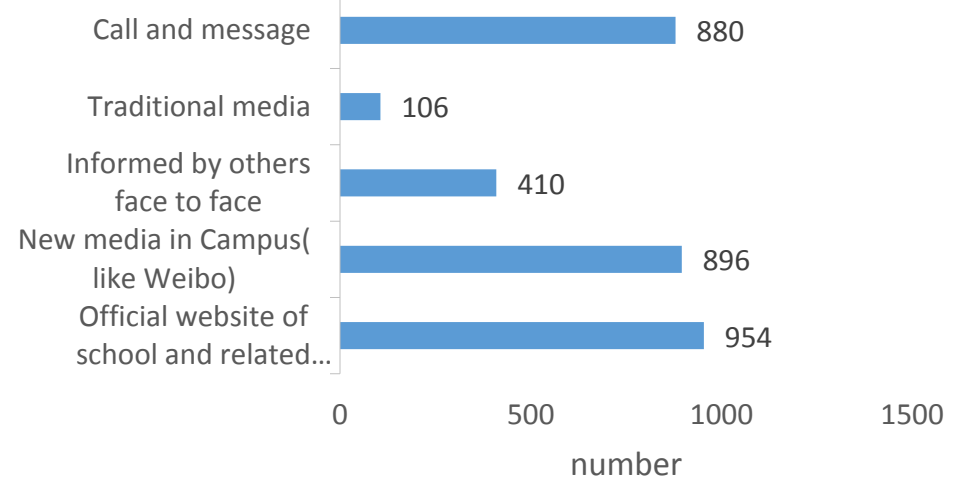

Fig. 1 Student's channels to know information in campus

\subsection{Challenge Brought by Internet Plus of the College Students Work.}

Just like an old saying goes, below a needle, above a thousand lines, student work pattern was unsuitable. School counsellors considered that daily affairs on their shoulder are still huge. Besides, repeated work consumed quantity of time. School counsellors couldn't take enough time to communicate with students, chats in face to face. However, almost all school counsellors said that they would like to communicate and become one with students. They just always felt that there needs a new idea to shorten the distance between teachers and students.

The rapid develop of the mobile internet and the widely-use of the intelligent terminal lead a result that the students absorb a lot of information which may contain unhealthy information. Students can be affected by that bad information easily because of the lack of the discernment. Students work is hard to launch under this information-explode situation.

Most students get more information from the mobile terminal than computer. And students widely express that the information service platform of school is not satisfied. At present, a number of universities are trying to discover the improved campus information providing pattern. There are some typical examples such as "Tongji Yun" developed by Tongji University, Hust APP developed 
by Huazhong University of Science and Technology, etc. But this software is transaction process system, which has no deep level application and cannot meet the current users' demand for intelligent service.

\section{Solution}

The Campus Micro-Platform that we proposed in this paper has three primary functions contains the news aggregator, the message notification, and the transaction schedule. The platform is designed to solve many problems we have met in student work include the communication inconvenience between teacher and student, the supervision lag of public sentiment, the miscellaneous transaction in student work and the unfavourable control for the student's thoughts.

The news aggregator, designed to aggregate the large number of news in campus, divide news into the form of news module and push the most closely and personalized news to user as much as possible. The news modules are composed with fixed module and exclusive module. The news in fixed module is edited and published by teachers in every colleges and it improved teacher's work efficiency and made the problem that teachers lack method to make political education, to arrange the student work and to construct rules solved. Exclusive module is arranged by the platform to ensure the timeliness and abundance of the news. And we observed systems strictly, strengthened the content management and propagated the positive energy energetically.

The message notification, is designed to provide a new form of notification and communication, and in the other hand it made the platform has a certain social attributes. The message notification is aimed at group which divided automatically by the platform according to school structures such as classes, grades and other student organizations. In this way, there is a significant improvement in the efficiency of communication within the group. All kinds of student work and notifications had a new way to notify. Platform provides an innovative feature called "Notification feedback". At the same time, "one key to confirm receipt" and "Notification reply" are designed to simplify the feedback processes within the context of the accuracy of the notification messaged.

The transaction schedule is designed for schedule remainder. The platform can extract the time and location form news and notifications intelligently and add to the corresponding schedule according to the type of event, the platform will remind user in time as well. Users can record the transaction they meet in campus into memo quickly without inputting a large amount of information. Student work contains a lot of meetings, lectures and other information, this feature can able to address the needs of information classification.

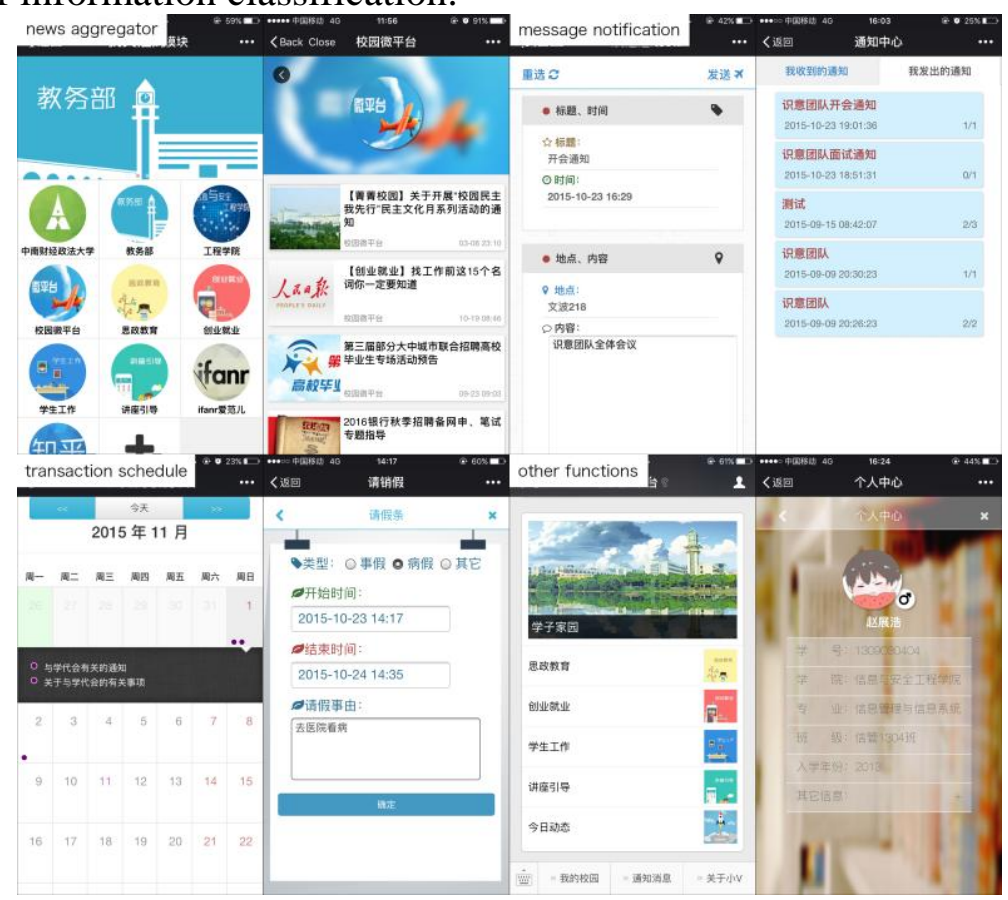

Fig. 2 The Campus Micro-Platform's system function module 


\section{Literature References}

The Campus Micro-Platform of this paper mentioned have been practiced and used in ZNUFE. And get a good response. During March to May in 2015, we have conducted a spot investigation in ZNUFE about present situations of student work, campus computing construction, campus information providing and so on [8]. On this basis, the develop of current student work management mode can be known. 1000 questionnaires in total were distributed, with the valid call-back rate of $98.3 \%$. The objects of questionnaires contained students in all grades, in which fresher occupied $27 \%$, sophomore occupied 29\%, junior took up 25\%, and senior took up 19\%. At the same time, interviews with school counsellors have been conducted.

\subsection{Students' Feedback.}

When we mentioned the questions about current student work, 51.7\% students gave scores between 70 and 85, 29.8\% students' provided scores are between 85 and 100. In conclusion, students' evaluation to school counsellors could be measured as basically satisfactory. Moreover, 76.8 percent of the students believed student work's intervention with Internet is really important. They thought student work is kind of tough, so there is not a strong willing to accept it. As for the question about which specific aspect of student work need to be motivated most, 368 chose information and notice transmission which occupied 37.4\%, 217 chose communication between student and school counsellors with domain $22.1 \%, 204$ chose ideological collection and guidance and students who chose student transaction processing amounted to 194 and occupied $19.7 \%$. The overall evaluation is shown in the Fig. 3

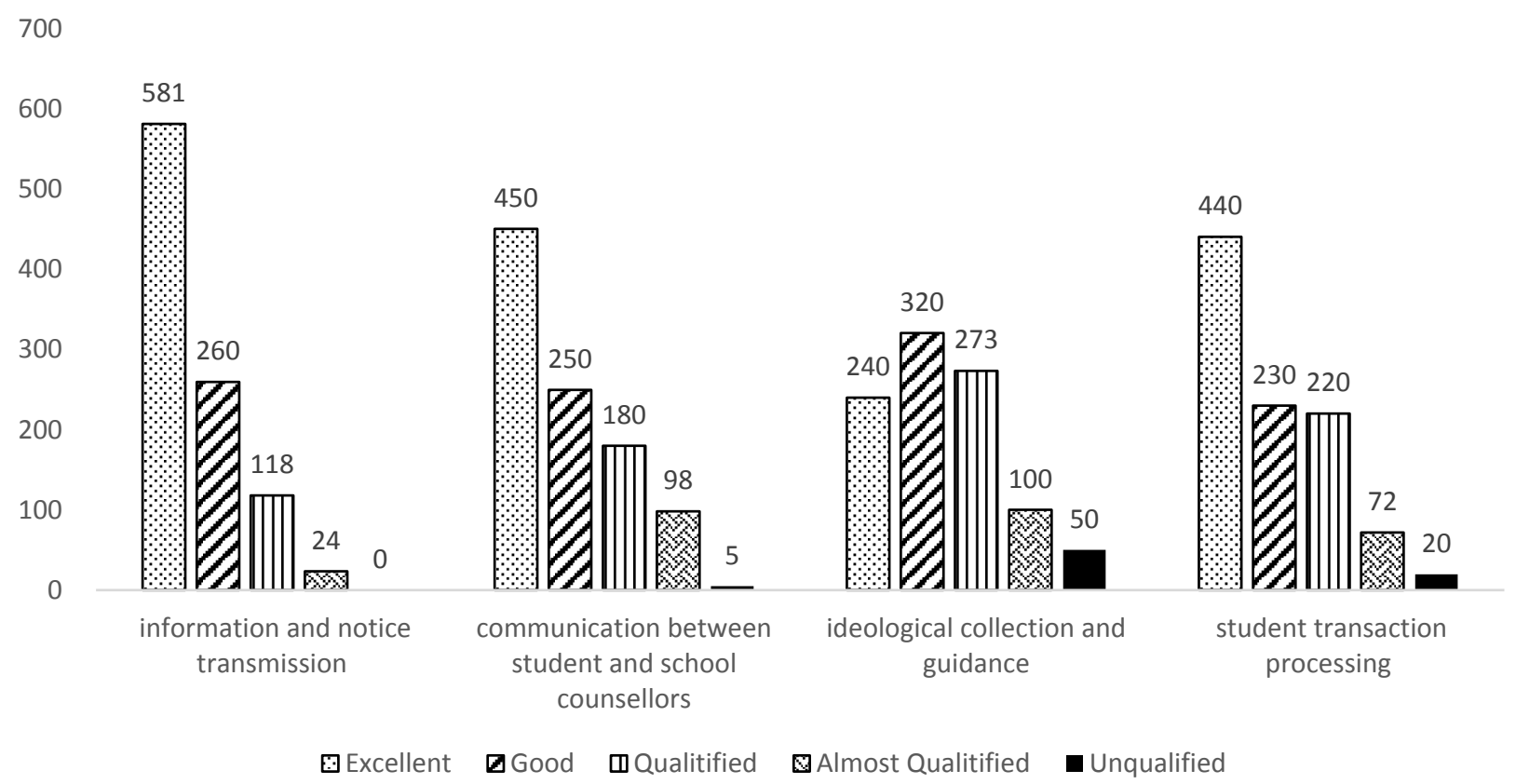

Fig. 3 The overall evaluation of student work after Campus Micro-platform applicate

\subsection{School Counsellors' Assessment. \\ Using real name authentication to ensure safety and trustiness}

Everyone in the platform must bind its account with its Student-ID or Stuff-ID and user must certify the operation in its mobile phone or Email. Therefore, one platform account is corresponded with one user. As everyone knows, it is difficult to supervise disadvantage of the platform include malicious user and garbage information. Using real name authentication make the supervision easily. At the same time, it is convenient for teacher to do student works such as guiding students' ideological state, supervising public sentiment and doing attendance registration.

\section{The open and convenient integration system}

In digital campus construction, there have been a number of perfect information systems for teachers and students, without the support of mobile internet is the only defect of these systems. The 
emergence of The Campus Micro-Platform can make these systems have a new live, so as to develop into a service platform that covering all aspects of the campus life. The platform has integrated the educational administration system in mobile terminal, provided querying results and other functions to facilitate students, at the same time, system used data analysis method, and processed data so that teachers can monitor the students' academic performance much better and have comprehensive understanding for each student.

The leave and sick leave system make the leave transitions become comprehensive information among counsellors, teachers and students. Checking attendance system regulate the behaviour of students through the bedroom roll call and the classroom roll call. The research group is trying to provide an open outside access, so that the major information systems can be integrated independently, and improving the scalability of the platform continuously.

\section{Accumulating reasonable data}

At present, information and data dispersed in various campus information systems. But The Campus Micro-Platform can be expected to break the compact coupling relationship between information and data in these elements such as teaching, management, research, service and it can enhance the fluidity of information and data. At same time, because of the real name authentication, the data accumulated during the process of platform's development can have higher quality [9]. In addition, the model of Micro-Platform could apply in various areas such as drug development and enterprise management [10].

A key feature of "Internet plus" is that leaping from IT (Information Technology) to DT (Data Technology) rapidly [11]. The Campus Micro-Platform combined the accumulated data with big data, cloud computing, data mining and other emerging technologies so that making the data not only stay in a simple retrieval and display levels, but finding hidden value at the back of the data and making intelligent judgement to a student, managing the ideological trend of student, to achieve a more refined and personalized service. In order that the student work can be more correct and more efficient based on the platform.

\section{Summary}

The new idea of student work had been practiced in Zhongnan University of Economics and Law, and most teachers and students gave high evaluation about it and the evaluation indicators of the platform all have a certain upgrade than before. The Campus Micro-Platform was designed for solving the problem that the low efficiency of information transfer between the information subjects in campus so that the student work could have a high speed. However, there were some deficiencies in this vision, the satisfaction couldn't reach the expectation of the research group. In addition, our group will introduce the advanced technology furthermore, such as using cloud computing to improve the function and achieve more deep application through data mining so that the platform can reveal better value.

The Campus Micro-Platform extended successfully provided a new way of the "Internet plus" concept in the field of high education, provided a feasible method for the further development of digital campus and made the student work conform to the development trend of the Internet, promoted reference of a full range contains innovation, content, means, system and mechanism as well.

\section{Acknowledgements}

This work was funded by Student's Platform for Innovation and Entrepreneurship Training Program (No.201510520090), Humanities and Social Sciences Research Project (20120047) and Theme Practice Activities Program for Primary CPC Organizations of Zhongnan University of Economics and Law in 2015-2016 (The practical exploration on Construction of CPC with "Internet plus" in university under the new normal). Sincerely thanks to our tutor Zhenxin Qu, Chuanming Yu, Chaoyang Liu and Maosheng Liu. 


\section{References}

[1]. Hequan Wu. The "Internet Plus" Action Plan: Opportunities and Challenges. Frontiers. Vol. 74 (2015) No. 10, p. 6-14.

[2]. Fei Li, Jingdong Zhang, Jinhui Huang, et al. Heavy metals in road dust from Xiandao District, Changsha city, China: Characteristics, health risk assessment and integrated source identification. Environmental Science and Pollution Research, 2016, DOI: 10.1007/s11356-016-6458-y

[3]. Moore G. C. Benbasat I. Development of an instrument to measure the perceptions of adopting an information technology innovation. Information Systems Research. Vol.2 (1991) No.3, p.192-222.

[4]. Zhuli Wang, Xiaoyu Li, Jin Lin. Smartphones and the "Internet + Class” : A New Thinking and New Pattern of Information Technology Integrated into Curriculum. Journal of Distance Education. Vol. 229 (2015) No. 4, p. 14-21.

[5]. MinyuWu, HuanLiu, YouqunRen. "Internet Plus Campus": A New Phase of "Smart Campus" Construction of Colleges. Journal of Distance Education.Vol. 229(2015) No.4, p.8-13

[6]. Bargh J.A., McKenna K. Y. A. The Internet and social life. Annual Review of Psychology, (2004) No.55, p.573-590.

[7]. Omarzu J. A disclosure decision model: determining how and when individuals will self-disclose. Personality \& Social Psychology Review (Lawrence Erlbaum Associates), Vol.2 (2004) No.4 p.174-185.

[8]. Wei Zhao, Yan Tian, ZhengLi. A Comparative Study of Teaching Quality Assessment Systems in Domestic and Foreign Universities. Technology and Innovation Management. Vol.32 (2011) No.5, p. 545-549

[9]. Fei Li, Jinhui Huang, Guangming Zeng, et al. Spatial risk assessment and sources identification of heavy metals in surface sediments from the Dongting Lake, Middle China. Journal of Geochemical Exploration.Vol.132(2013) No.9, p.75-83

[10]. Liu Chaoyang, Chan Chi Bun, Ye Keqiang. 7, 8-dihydroxyflavone, a small molecular TrkB agonist, is useful for treating various BDNF-implicated human disorders. Translational Neurodegeneration. 2015, 5: 2047-9158

[11]. Xin Xu, Xinning Su. Building a New Generation Digital Campus of University.New Technology of Library and Information Service.Vol.119 (2005) No.1, p.48-55 